\title{
Assessment of the relationship between the maxillary sinus and the canine root tip using cone beam computed tomography
}

\author{
Leila Khojastepour ${ }^{1}$, Najmeh Movahhedian ${ }^{1 *}$, Mohadeseh Zolghadrpour ${ }^{2}$ and \\ Mohammad Mahjoori-Ghasrodashti ${ }^{3}$
}

\begin{abstract}
Background: The purpose of the present study is to investigate the relationship between the maxillary sinus and the canine root apices in cone beam computed tomographic images (CBCT) and to assess the amount of extension of the maxillary sinus to the anterior region of the jaw in different sexes and age groups.

Methods: CBCT of 300 individuals (154 males and 146 females) over 20 years (with a mean age of $35.12 \pm 8.40$ years) were evaluated. The subjects were categorized into three age groups (20-30, 30-40, and 40-50 years). When the maxillary sinus extended to the canine area, the vertical distance between them was measured, and their relationship was classified into three types: I (more than $2 \mathrm{~mm}$ distance), II (less than $2 \mathrm{~mm}$ distance or in-contact), and III (interlock).

Results: 413 out of 600 maxillary sinuses (68.8\%) were extended into the canine area or beyond. Among them, 15 maxillary sinuses pneumatized into the incisor area (2.5\%). The prevalence of the maxillary sinuses extended to the anterior region of the jaw was not significantly different between genders. However, it was significantly less frequent in the older age group and more frequent on the left side. In addition, the mean amount of anterior extension of the maxillary sinus ( $\mathrm{mm}$ ) was significantly lower in the older age group. Type I was the most frequent vertical relationship between the maxillary sinuses and canine apices with no significant difference in gender, side, and age groups.
\end{abstract}

Conclusions: In most cases, the maxillary sinus extended to the canine area and sometimes reached the incisor region. This necessitates paying more attention to the maxillary anterior sextant during surgical procedures.

Keywords: Maxillary sinus, Anterior extension, Canine apex, Incisor, Cone beam computed tomography

\section{Background}

The maxillary sinuses are the most extensive paranasal sinuses, which are very small at birth but expand by physiologic pneumatization until completion of skeletal development [1] or around 20 years [2]. The maxillary sinus often extends from the distal aspect of the canine tooth to the posterior wall of the maxilla above the tuberosity

\footnotetext{
*Correspondence: movahedian@sums.ac.ir

${ }^{1}$ Department of Oral and Maxillofacial Radiology, School of Dentistry,

Shiraz University of Medical Sciences, Qom Abad, Ghasrodasht St., Shiraz,

Iran

Full list of author information is available at the end of the article
}

[3]. Occasionally, general practitioners misinterpret the pneumatization of the anterior part of the maxilla by the maxillary sinus as a cystic lesion on intraoral or panoramic radiographs [4]. Evaluation of the relationship between the maxillary sinus and the dentition is essential for dental procedures, such as implant or apical surgeries and orthodontic treatments [5, 6]. Moreover, assessing these anatomical structures is also important since they provide a pathway for infection to spread from the periodontal or peri-apical lesions into maxillary sinuses, which can cause maxillary sinusitis [7-9].

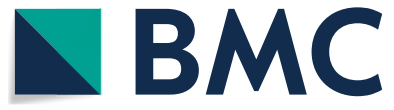

(c) The Author(s) 2021. This article is licensed under a Creative Commons Attribution 4.0 International License, which permits use, sharing, adaptation, distribution and reproduction in any medium or format, as long as you give appropriate credit to the original author(s) and the source, provide a link to the Creative Commons licence, and indicate if changes were made. The images or other third party material in this article are included in the article's Creative Commons licence, unless indicated otherwise in a credit line to the material. If materia is not included in the article's Creative Commons licence and your intended use is not permitted by statutory regulation or exceeds the permitted use, you will need to obtain permission directly from the copyright holder. To view a copy of this licence, visit http://creativecommons.org/licenses/by/4.0/. The Creative Commons Public Domain Dedication waiver (http://creativecommons.org/publicdomain/zero/1.0/) applies to the data made available in this article, unless otherwise stated in a credit line to the data. 
Two- or three-dimensional (2D or 3D) imaging has been used for evaluating paranasal sinuses. However, in cases with accompanying signs and symptoms regarding sinuses or the need for a thorough examination of sinuses prior to surgeries, 3D imagings are the modalities of choice [9]. In this regard, cone-beam computed tomography $(\mathrm{CBCT})$ provides accurate and distortion-free images of the craniofacial bones with lower absorbed radiation dose compared with multi-slice computed tomography [10-12].

Several studies evaluated the relationships between the posterior teeth and the maxillary sinus [4, 13-19], while the anterior part of the maxilla is often assumed as a relatively safe region for surgical interventions. Based on a recent CBCT study [4], the maxillary sinus extends to the canine area in $68.9 \%$ of cases and the incisor region in $15.5 \%$. The high frequency of the sinus extension to the canine tooth area necessitates a thorough evaluation of the region regarding the relationship between the maxillary sinus and the dentition. However, so far, there has been only one CBCT study considering the relationship between the canine and the maxillary sinus [20]. Oishi et al. [20] evaluated the proximity of the canine and posterior teeth to the maxillary sinus floor in the standard coronal and sagittal planes and reported significant differences between the measurements in these two planes. This difference was greater for the canine teeth. This can be due to the curved anatomy of the maxilla and the unique position of the canine tooth in the jaw. It seems that corrected planes parallel and perpendicular to the tooth long axis are necessary for more accurate and reliable results regarding the relationship between the canine tooth and the adjacent structures.

The present study aimed to assess the location of the anterior border of the maxillary sinus concerning teeth and the amount of anterior extension of the maxillary sinus (AEMS) beyond the canine tooth long axis and also the vertical distance between the maxillary sinus floor and the canine apices in different sexes and age groups using corrected $\mathrm{CBCT}$ planes.

\section{Methods}

This cross-sectional study has been performed following the Declaration of Helsinki and was approved by the Human Ethics Review Committee of the Faculty of Dentistry, University of Medical Sciences, Shiraz, Iran (\# IR Sums.Dental.REC.1399.020).

1430 CBCT scans of patients who attended the Oral and Maxillofacial Department of Shiraz Dental School (from May 2017 to May 2020) were reviewed retrospectively. CBCT images were taken for different purposes other than the present study. Written informed consent was obtained from all the patients at the time of radiographic examination for the possible use of their anonymous information in future researches, which may be published. Personal data of all individuals was kept undisclosed. In the end, 300 scans (154 men and 146 women with mean age of $35.12 \pm 8.40$ years) met the study criteria.

To be included in the study, the field of view of the CBCT images should cover the entire maxilla of individuals over 20 years, and both maxillary canines should completely erupt and develop. Exclusion criteria were distorted CBCT images due to metallic or motion artifacts, history of previous apical surgery, evidence of root resorption/fracture, intra-bony pathologies, supernumerary/missing/extracted or impacted teeth in the maxilla, congenital anomalies, or severe jaw deformities. In addition, high-buccal canines, not being in line with the incisal/occlusal surface of the dentition, were excluded from the study.

All CBCT images were obtained using the New Tom Evo CBCT unit (QR S.R.L. Company, Verona, Italy) with the following technical parameters: $3 \mathrm{~mA}, 1.8$ exposure time, $110 \mathrm{Kvp}, 0.3 \mathrm{~mm}$ voxel size, axial pitch, and axial thickness of $0.3 \mathrm{~mm}$. The Frankfort horizontal plane of all the subjects was parallel to the floor when acquiring the images. All the measurements were done using NNT software (NNT 9.2 Image Works, Verona, Italy) by two oral and maxillofacial radiologists with consensus. The same observers re-evaluated One-third of CBCT scans (100) after a two-week interval.

The study sample was categorized into three age groups: $20-30,30-40$, and $40-50$. The subjects were distributed evenly in these age groups as each category of age included 100 scans (200 maxillary sinuses). The distribution of the study subjects in these age groups is presented in Table 1 . The evaluators marked the most anterior limit of the anterior border of the maxillary sinus on the axial image for each subject. Then panoramic view was reconstructed based on the curved line drawn parallel to the dental arch at the cervical level of the dentition on the axial image. The axial and reformatted panoramic views served as the reference image for localizing the anterior limit of the maxillary sinus in the cross-sectional images. Bucco-lingual cross-sections were prepared perpendicular to the dental arch with $0.5 \mathrm{~mm}$ thickness and interval (Fig. 1). Then we recorded the location of the anterior border of the maxillary sinus in relation to different teeth. In cases with maxillary sinus extension to the canine region, the following evaluations were done: (1) AEMS beyond the canine tooth long axis; (2) the vertical relationship between the maxillary sinus floor and canine apices, and (3) the absolute vertical distance between the maxillary sinus floor and floor of the nasal fossa (MS-NF). 
Table 1 Comparison of the amount of maxillary sinus extension between different sexes, sides and age group

\begin{tabular}{|c|c|c|c|c|}
\hline & \multicolumn{2}{|c|}{$\begin{array}{l}\text { Extension of maxillary sinus } \\
\text { related to the canine long axis }\end{array}$} & \multirow[t]{2}{*}{$\begin{array}{l}\text { Total } \\
\mathrm{N}(\%)\end{array}$} & \multirow[t]{2}{*}{$p$ Value* } \\
\hline & $\begin{array}{l}\text { Anterior } \\
\mathrm{N}(\%)\end{array}$ & $\begin{array}{l}\text { Posterior } \\
\text { N (\%) }\end{array}$ & & \\
\hline \multicolumn{5}{|l|}{ Sex } \\
\hline Male & $207(67.21)$ & $101(32.79)$ & $308(100)$ & 0.377 \\
\hline Female & $206(70.55)$ & $86(29.45)$ & $292(100)$ & \\
\hline \multicolumn{5}{|l|}{ side } \\
\hline Right & $191(63.67)$ & $109(36.33)$ & $300(100)$ & 0.006 \\
\hline Left & $222(74.00)$ & 78 (26.00) & $300(100)$ & \\
\hline \multicolumn{5}{|c|}{ Age group } \\
\hline $20-30$ & $149(74.50)$ & $51(25.50)$ & $200(100)$ & 0.001 \\
\hline $30-40$ & $150(75.00)$ & $50(25.00)$ & $200(100)$ & \\
\hline $40-50$ & $114(57.00)$ & $86(43.00)$ & 200 (100) & \\
\hline
\end{tabular}

N: Number, \%: Percent

The number of slices (cross-sections) with sinus pneumatization beyond the canine tooth long axis were counted and multiplied by the slice thickness $(0.5 \mathrm{~mm})$ to calculate AEMS beyond the canine tooth long axis $($ AEMS $=$ Number of slices $\times$ Slice thickness $)$. For example, if maxillary sinus pneumatization is noticed on eight slices beyond the canine tooth long axis, the AEMS would be $4 \mathrm{~mm}(8 \times 0.5)$ (Fig. 2).

The canine tooth long axis was defined as the line passing through the center of the tooth connecting the middle point of the incisal edge to the apex.

The vertical relationship between the maxillary sinus floor and canine teeth apices was assessed based on the following classification (Fig. 3):

Type I Apex located below the sinus floor with more than $2 \mathrm{~mm}$ distance

Type II Apex located below the sinus floor with less than $2 \mathrm{~mm}$ distance (Type II a) or was in contact (Type II b).

Type III Apex located above the sinus floor

Figure 4 depicts how the vertical distance between the maxillary sinus floor and the nasal floor was measured.

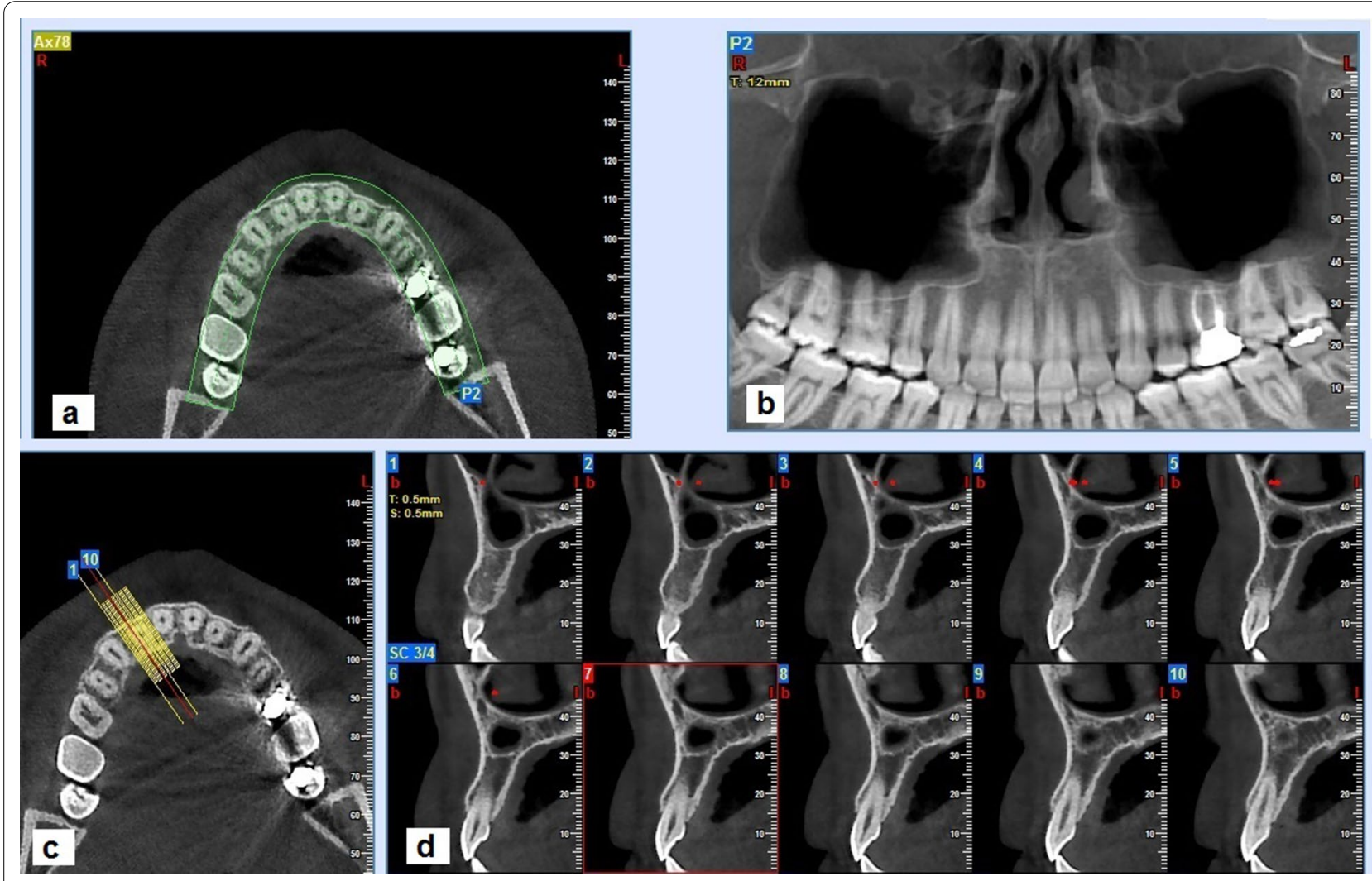

Fig. 1 a Axial image and curved line which used for panoramic reconstruction. b Reconstructed panoramic image. c Reference axial image for preparing buccolingual cross-sections. d Buccolingual cross-sections perpendicular to dental arch with $0.5 \mathrm{~mm}$ thickness and interval in a case of maxillary sinus pneumatization into the lateral incisor area 


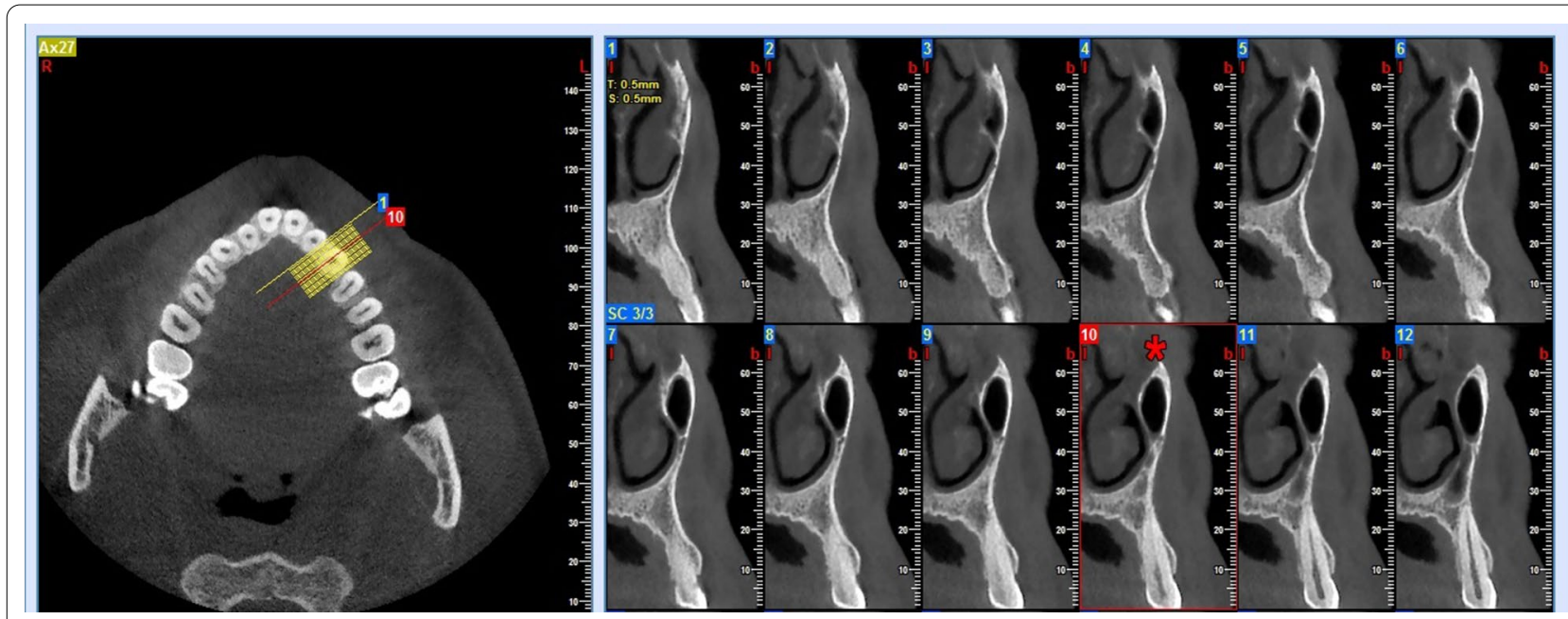

Fig. 2 A case with the maxillary sinus extended to the canine area. A star has marked the cross-section passing through the tooth-long axis. In this case, the maxillary sinus can be detected in eight cross-sections beyond the canine tooth long axis. So, the AEMS, in this case, is equal to $4 \mathrm{~mm}$ $(8 \times 0.5)$

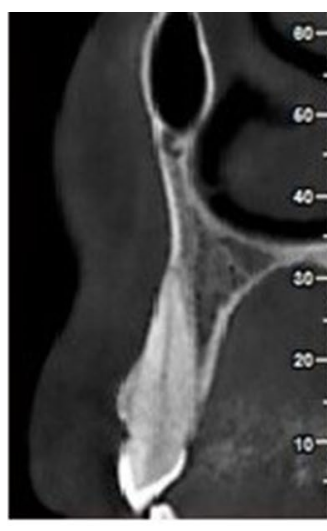

Type I

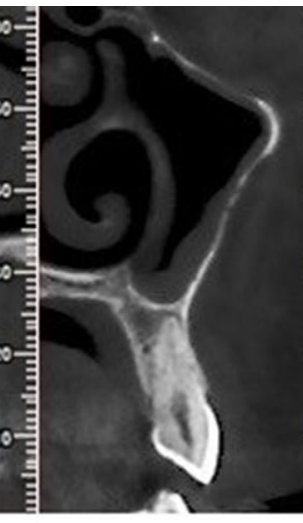

Type II a

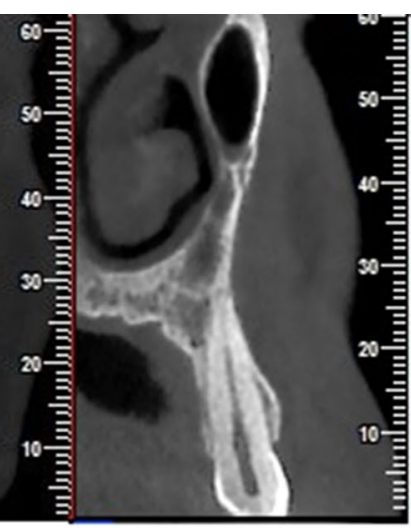

Type II b

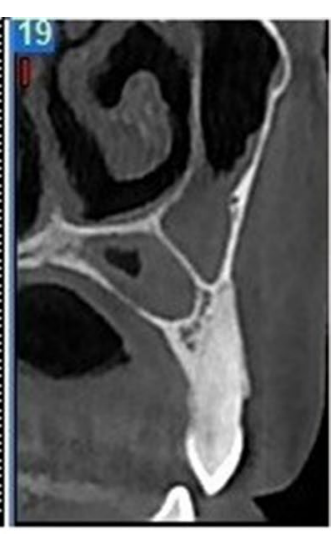

Type III

Fig. 3 Three types of the vertical relationship between the maxillary sinus floor and canine apex on buccolingual CBCT cross-sections: Type I (more than $2 \mathrm{~mm}$ distance), II a (less than $2 \mathrm{~mm}$ distance), II b (in contact), and III (interlock) relationship

\section{Statistical analyses}

Statistical analyses were conducted using the SPSS software (version 20; IMB; Chicago; IL). Quantitative and qualitative variables were described by mean \pm standard deviation (SD) and frequency (percent). We used the Chi-square test to compare the AEMS and the vertical relationship between the maxillary sinus floor and canine apex in different sexes, sides, and age groups. ANOVA test was performed to compare the mean distances $(\mathrm{mm})$ of MS-NF and the anterior extension of the maxillary sinus in different age groups. $p$ value $<0.05$ was considered statistically significant. The intra-class correlation coefficient (ICC) was also used to evaluate the intra-examiner error.

\section{Results}

CBCT images of 300 individuals (600 maxillary sinuses (met the study inclusion criteria and were evaluated. The mean age of subjects was $35.12 \pm 8.40$ years. The study sample consisted of $146(48.7 \%)$ women with a mean age of $34.66 \pm 8.78$ years and $154(51.3 \%)$ men with a mean age of $35.56 \pm 8.03$ years old. ICC was $96 \%$ which is considered a perfect agreement. 


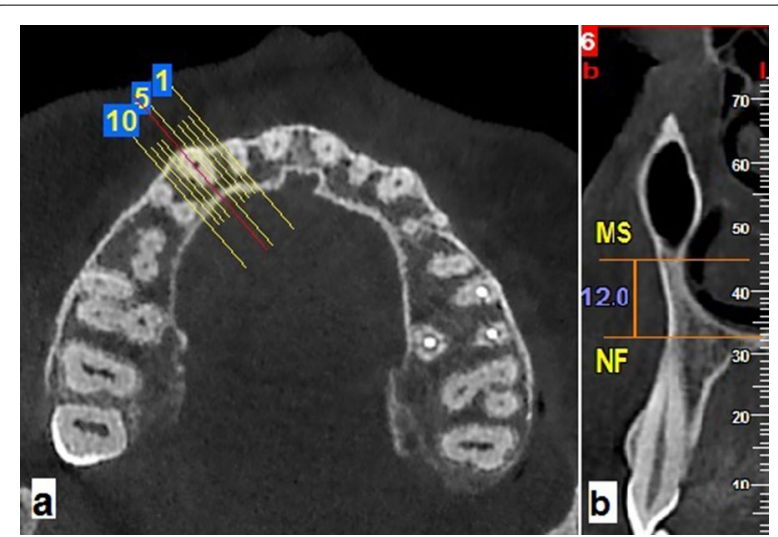

Fig. 4 a axial reference image and $\mathbf{b}$ buccolingual cross-section for measurement of the distance between floors of the maxillary sinus (MS) and nasal fossa (NF) at canine tooth long axis

Out of 600 maxillary sinuses, 413 (68.83\%) extended into the canine area or beyond. 15 sinuses (2.5\%), belonged to 8 subjects, involved the incisor region. The location of the anterior border of maxillary sinuses in relation to other teeth was as follows: 149 (24.83\%) into the first premolar, 36 (6\%) into the second premolar, and $2(0.33 \%)$ into the first molar area.

Sinus extension had bilateral symmetry in 244 individuals (81.33\%) and was non-symmetrical in 56 (18.66\%). Among cases with symmetric sinus extension, in 178 patients $(59.33 \%)$, the maxillary sinus extended into the canine region, and in 66 patients (22\%), it was located posterior to the canine area bilaterally.

Table 1 shows the maxillary sinus extension related to the canine tooth long axis in different sexes, sides, and age groups. Extension beyond the canine tooth long axis was significantly more frequent on the left side ( $p$ value $=0.006)$ and less frequent in the older age group $(40-50$ years old $)(p$ value $=0.001)$. No sex difference was found in the prevalence of extension of the maxillary sinus to the anterior region of the jaw ( $p$ value $=0.377$ ).

Regarding the vertical relation between the sinus floor and canine apices, type I was the most frequent. 351 out of $413(84.99 \%)$ maxillary sinuses extended to the canine area had type I vertical relation with canine apices. Type II and III were noted in 37(8.96\%) and 25 (6.05\%) of such maxillary sinuses, respectively. As shown in Table 2, there were no significant differences between vertical relation of the maxillary sinus floor and canine apices in different sexes, sides, and age groups ( $p$ value $=0.153,0.355$, and 0.111 , respectively).

In cases with extended maxillary sinus into the canine region (type I and II), the mean vertical distance between the maxillary sinus floor and canine apex was $11.99 \pm 5.97 \mathrm{~mm}$. 25 canine apices were located above
Table 2 Comparison of maxillary sinus and canine apex vertical relationship considering sex, side and age groups

\begin{tabular}{llllll}
\hline Variable & \multicolumn{3}{l}{$\begin{array}{l}\text { Maxillary sinus and canine apex } \\
\text { relation }\end{array}$} & Total & p Value* \\
\cline { 2 - 4 } & $\begin{array}{l}\text { Type I } \\
\text { N (\%) }\end{array}$ & $\begin{array}{l}\text { Type II } \\
\text { N (\%) }\end{array}$ & $\begin{array}{l}\text { Type III } \\
\text { N (\%) }\end{array}$ & & \\
\hline Sex & & & & & \\
Male & $169(81.64)$ & $23(11.11)$ & $15(7.25)$ & $207(100)$ & 0.153 \\
Female & $182(88.35)$ & $14(6.79)$ & $10(4.85)$ & $206(100)$ & \\
Side & & & & & \\
Right & $160(83.77)$ & $16(8.37)$ & $15(7.85)$ & $191(100)$ & 0.355 \\
Left & $191(86.03)$ & $21(9.50)$ & $10(4.52)$ & $222(100)$ & \\
Age group & & & & & \\
20-30 & $124(83.22)$ & $15(10.07)$ & $10(6.71)$ & $149(100)$ & 0.111 \\
$30-40$ & $122(81.33)$ & $15(10.00)$ & $13(8.67)$ & $150(100)$ & \\
$40-50$ & $105(92.11)$ & $7(6.14)$ & $2(1.75)$ & $114(100)$ & \\
\hline
\end{tabular}

$\mathrm{N}$ : Number, \%: Percent

the maxillary sinus floor (Type III). Their distances to the maxillary sinus floor were evaluated separately. The mean distance in this group was $4.71 \pm 3.83 \mathrm{~mm}$. The distance between the maxillary sinus floor and canine apex was not statistically different between age groups ( $p$ value $=0.207$ ). There was no significant difference between the right and left sides in this regard.

In most cases with extended maxillary sinuses to the canine area, the nasal floor was located below the sinus floor. The mean absolute distance of MS-NF was $10.13 \pm 4.76 \mathrm{~mm}$ in the study population, $9.84 \pm 4.77 \mathrm{~mm}$ for the right, and $9.49 \pm 4.60 \mathrm{~mm}$ for the left side. The difference between these values was not statistically significant.

The mean of AEMS beyond the maxillary canine long axis was $2.03 \pm 1.17 \mathrm{~mm}$ with a maximum extension of $16 \mathrm{~mm}$. This value was $2.25 \pm 1.18 \mathrm{~mm}$ for the left side which was significantly more than the right side $(2.04 \pm 1.08 \mathrm{~mm})$. Extensive pneumatization of the maxillary sinus is detected in one case, which involved the entire hard palate and extended to the central incisor region (Fig. 5).

Table 3 shows that the mean AEMS was significantly lower in the 40-50 years age group compared to the other age groups $(p$ value $=0.001)$. Moreover, the mean distance of MS-NF was significantly higher in the same age group than the two others $(p$ value $=0.001)$.

\section{Discussion}

In the present study, we evaluated the amount of anterior extension of maxillary sinus beyond the long axis of the maxillary canine and the relationship between the root 


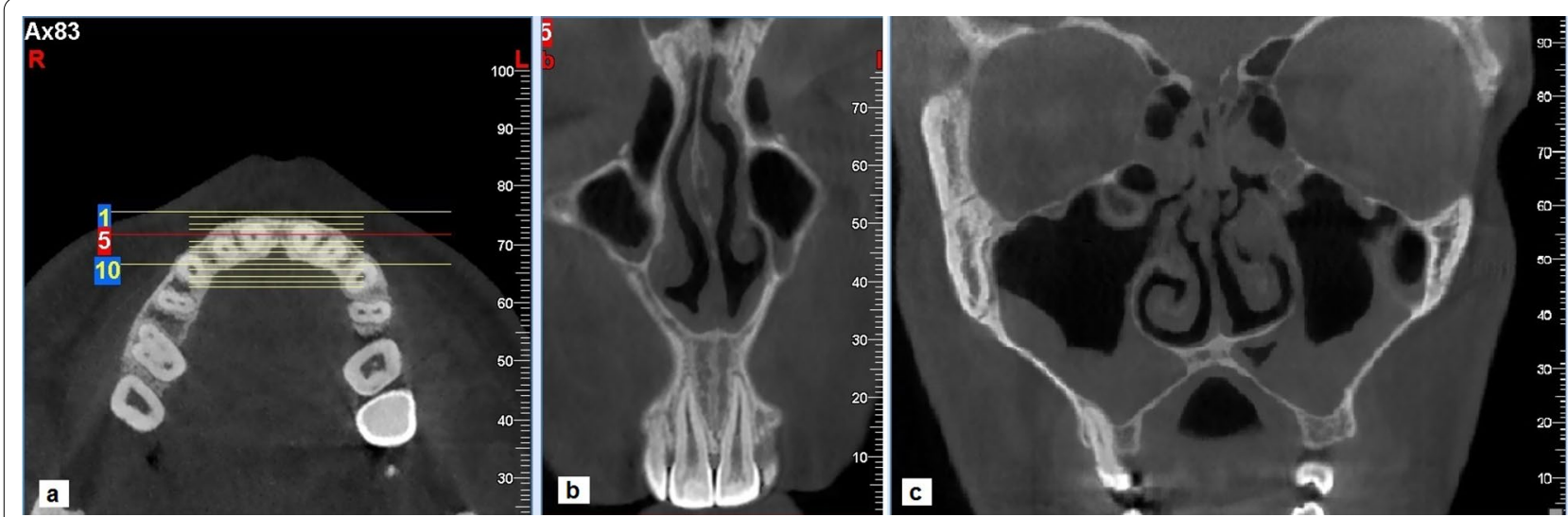

Fig. 5 A case of extensive maxillary sinus pneumatization: $\mathbf{a}$ reference axial image $\mathbf{b}$ the extension to the central incisor region. $\mathbf{c}$ involvement of the entire hard palate

Table 3 Comparison of the anterior extension of maxillary sinus beyond canine tooth and the distances between the maxillary sinus and nasal floors between age groups

\begin{tabular}{lll}
\hline Age group & $\begin{array}{l}\text { AEMS } \\
\text { Mean } \pm \text { SD }(\mathbf{m m})\end{array}$ & $\begin{array}{l}\text { MS-NF } \\
\text { Mean } \pm \text { SD (mm) }\end{array}$ \\
\hline $20-30$ & $2.23 \pm 1.147^{\mathrm{a}}$ & $9.24 \pm 4.57^{\mathrm{a}}$ \\
$30-40$ & $2.19 \pm 1.189^{\mathrm{a}}$ & $10.04 \pm 4.93^{\mathrm{a}}$ \\
$40-50$ & $1.54 \pm 1.044^{\mathrm{b}}$ & $11.43 \pm 4.53^{\mathrm{b}}$ \\
pValue* & 0.001 & 0.001 \\
\hline
\end{tabular}

AEMS anterior extension of the maxillary sinus, MS-NF distance between maxillary sinus and nasal floor

*Mean values with at least one same letter in superscript were not statistically different

apex of the permanent maxillary canine and the maxillary sinus floor in $300 \mathrm{CBCT}$ images.

The proximity of the sinus floor and root apices of the maxillary teeth is critical in several clinical procedures such as endodontic surgery, orthodontic treatment, and implant placement. CBCT scans, with dedicated 3D software, allow image reconstruction in three orthogonal planes and precise morphometric measurements, which provide accurate information for case selection, treatment planning, and avoiding collateral damage during surgery [10-12].

The result of the present study shows that most of the maxillary sinuses $(68.83 \%)$ extended to the canine area, which is almost equal to Zhang et al. finding (68.9\%) [4]. In contrast, Kim et al. [21] and Kopecka et al. [22] reported much lower percentages of canine area pneumatization by maxillary sinus, $33 \%$, and $2.4 \%$, respectively. Regarding the pneumatization of the incisor region, Zhang et al. [4] reported a frequency of $15.5 \%$ (12.1\% in lateral and $3.4 \%$ in central incisor) in their study population. In the present study, however, the anterior border of the maxillary sinus reached the incisor area in only $2.5 \%$ of sinuses. The difference in the percentages reported by the studies may be due to ethnicity and the differences in methodology, including the approach used for localizing the maxillary sinus and the number of subjects.

In this study, most of the maxillary sinuses (81.33\%) had bilateral symmetry in the location of the anterior border in the jaw. This finding was in accordance with previous studies [2, 23, 24]. Comparably, Shahbazian et al. [25] reported the symmetric morphology of maxillary sinus in $83 \%$ of their cases, and according to Hamdy et al. [26], the average linear craniocaudal, anteroposterior, and mediolateral measurements were almost bilaterally matched in all cases. Based on our results, bilateral symmetry was even more common in those maxillary sinuses which extended into the canine area. Further studies are required to confirm this result.

The frequency of maxillary sinus extended to the anterior region was similar in both sexes in the present study. No study evaluated this relationship previously.

The frequency of maxillary sinus extended to the anterior region, and the mean AEMS beyond the canine long axis was significantly lower in older cases (40-50 years) compared with the other age groups. Additionally, in the vertical dimension, the MS-NF was significantly higher in the older age group. These findings confirm those of Belgin et al. [23], Takahashi et al. [27] and VelascoTorres et al. [28] who found decreasing maxillary sinus volume with increasing age. Jun et al. [1] also showed that the maxillary sinus increases in size until the completion of skeletal development in both sexes. Then, an age-related decrease occurs in its volume. Similarly, Ariji et al. [2] reported increasing maxillary sinus volume up to 20 years of age and a declining process subsequently. Contrary to all these findings, Sahlstrand-Johnson et al. 
[29] reported that maxillary sinus volume was not related to age in their study sample.

Oishi et al. [20] found a significant negative correlation between age and the distance of the maxillary sinus floor to the root apices of all teeth (posterior teeth and canine) in CBCT images. The same result was found by AL Qasab et al. [30] regarding the distance between the canine apex and maxillary sinus floor in periapical radiographs. In the present study, the vertical distance between the maxillary sinus floor and canine apex was not statistically related to age. Further research with a larger sample size is needed to clarify these conflicting results.

As part of this study, it is found that when the maxillary sinus extended to the canine area, the apices were most commonly (84.99\%) located below the sinus floor and at more than $2 \mathrm{~mm}$ distance (type I). It was followed by types II and III relationship with much less percentage $(8.96 \%$ and $6.05 \%$ respectively). This order was in accordance with a recent study by Oishi et al. [20]. They defined type 0 for those cases in which the sinus floor did not appear above the root apices. Type I, II, and III are reserved for separate, in-contact, and interlock relationships between the maxillary sinus floor and canine apices. They reported that whenever maxillary sinus appeared above the canine apices, type I was the most, and type III was the least frequent relationship, similar to our findings.

Oishi et al. [20] assessed the proximity of the posterior teeth and the canine tooth to the maxillary sinus floor in standard sagittal and coronal planes and did not consider the anatomic curvature of the jaw, which is especially important in the canine area. In contrast, in the present study, the classification and measurements were done based on bucco-lingual cross-sections perpendicular to the dental arch of each side of the jaw. This corrected plane seems to be more reliable for evaluating the relationship and distance of the root apices and the sinus floor. In the study of Oishi et al. [20], the subjects was not evenly distributed in according to age and most of their sample (184 subjects) were between 18-29 years. Moreover, their sample size weighted toward the female group (225), which was three times more than the male group (76). To minimize the possible biases and to have more accurate results, we tried to have an even subject distribution in different age groups (each age group contained 100 subjects/200 maxillary sinuses) as well as having similar numbers of male (154) and female (146) subjects. However, based on the limited number of older individuals meeting the study's inclusion criteria, we set the upper age at 50 years old. We encourage future studies with a broader age span to overcome this limitation.

Another limitation of the present study is that the effect of facial biotypes has not been considered in the design of the present study. Okşayan et al. [31] reported lower values in maxillary sinus length and width in highangle subjects. Costea et al. [32] found that the relationship between the maxillary second molar root apices and the maxillary sinus floor is affected by the facial biotype. Future studies can address whether the different facial biotypes influence the canine tooth and maxillary sinus relationship.

\section{Conclusions}

Within the limitations of this study, the following conclusions may be drawn:

1. Most of the maxillary sinuses extended to the canine area

2. In most cases with the maxillary sinus extended to the canine area, the canine apex was located more than $2 \mathrm{~mm}$ below of maxillary sinus floor

3. The maxillary sinus could extend into the incisor region. This extension is of particular importance for surgical procedures and implant treatment in the maxillary anterior region

4. Extension of the maxillary sinus to the anterior part of the maxilla was less frequent in the older age group compared to the younger subjects

5. The mean absolute distance between the maxillary sinus and nasal floor was higher in the older age group

\section{Abbreviations}

CBCT: Cone-beam computed tomography; 2D or 3D: Two- or three-dimensional; AEMS: Anterior extension of the maxillary sinus; MS-NF: Vertical distance between maxillary sinus floor and floor of the nasal fossa; SD: Standard deviation; ICC: Intra-class correlation coefficient.

\section{Acknowledgements}

The authors thank the Vice-Chancellory of Shiraz University of Medical Science for supporting this research (Grant \# 20827). This manuscript is based on the thesis by Dr. Mohadeseh Zolghadrpour. We also thank Dr. Mehrdad Vossoughi of the Center for Research Improvement of the School of Dentistry for the statistical analysis.

\section{Authors' contributions \\ All authors contributed to the study's conception and design. Material prepa- ration, data collection, and analysis were performed by L.Kh. and N.M., and M.Z. L.Kh. wrote the first draft of the manuscript; reviewed and edition was done by N.M. and M.M. All authors read and approved the final manuscript.}

\section{Funding}

This study was funded by Shiraz University of Medical Science (Grant \# 20827). Although the Human Ethics Review Committee of Shiraz University of Medical Sciences (\# IR Sums.Dental.REC.1399.020) approved the study, they did not have any role in the study design. The study samples were also collected from the archive of the Oral and Maxillofacial Radiology Department of Shiraz University of Medical Science. They did not have any role in data analysis, interpretation of the data, and writing the manuscript. 


\section{Availability of data and materials}

The datasets used and analyzed during the current study are available from the corresponding author on reasonable request.

\section{Declarations}

\section{Ethics approval and consent to participate}

The Human Ethics Review Committee approved this study of the Faculty of Dentistry, University of Medical Sciences, Shiraz, Iran (\# IR Sums.Dental. REC.1399.020)

\section{Consent to participate}

Written consent was taken at the time of radiographic examination from all the patients to use their anonymous information in future research. The form will surely be available upon the journal requirement.

\section{Competing interests}

The authors declare that they have no conflict of interest.

\section{Author details}

1 Department of Oral and Maxillofacial Radiology, School of Dentistry, Shiraz University of Medical Sciences, Qom Abad, Ghasrodasht St., Shiraz, Iran. ${ }^{2}$ Student Research Committee, School of Dentistry, Shiraz University of Medical Sciences, Shiraz, Iran. ${ }^{3}$ Eastman Institute for Oral Health, Rochester, USA.

Received: 29 January 2021 Accepted: 28 June 2021

Published online: 10 July 2021

\section{References}

1. Jun B-C, Song S-W, Park C-S, Lee D-H, Cho K-J, Cho J-H. The analysis of maxillary sinus aeration according to aging process; volume assessment by 3-dimensional reconstruction by high-resolutional CT scanning. Otolaryngol Head Neck Surg. 2005;132:429-34.

2. Ariji Y, Kuroki T, Moriguchi S, Ariji E, Kanda S. Age changes in the volume of the human maxillary sinus: a study using computed tomography. Dentomaxillofac Radiol. 1994;23:163-8.

3. Mallya S, Lam E. White and Pharoah's oral radiology e-book: principles and interpretation: Second South Asia Edition E-Book: Elsevier; 2019.

4. Zhang YQ, Yan XB, Meng Y, Zhao YN, Liu DG. Morphologic analysis of maxillary sinus floor and its correlation to molar roots using cone beam computed tomography. Chin J Dent Res Off J Sci Sect Chin Stomatol Assoc (CSA). 2019;22:29-36.

5. Drake R, Vogl AW, Mitchell AW. Gray's Anatomy for Students E-Book: Elsevier Health Sciences; 2009.

6. Misch CE. Contemporary implant dentistry. Implant Dent. 1999;8:90.

7. Hauman C, Chandler N, Tong D. Endodontic implications of the maxillary sinus: a review. Int Endod J. 2002;35:127-41.

8. Monkhouse S. Cranial nerves: functional anatomy. Cambridge: Cambridge University Press; 2005.

9. Zhang B, Wei Y, Cao J, Xu T, Zhen M, Yang G, et al. Association between the dimensions of the maxillary sinus membrane and molar periodontal status: a retrospective CBCT study. J Periodontol. 2020;91:1429-35.

10. Nascimento HAR, Andrade MEA, Frazão MAG, Nascimento EHL, Ramos-Perez FMM, Freitas DQ. Dosimetry in CBCT with different protocols: emphasis on small FOVs including exams for TMJ. Braz Dent J. 2017;28:511-6.

11. Pauwels R. Cone beam CT for dental and maxillofacial imaging: dose matters. Radiat Prot Dosim. 2015;165:156-61.

12. Szabo BT, Aksoy S, Repassy G, Csomo K, Dobo-Nagy C, Orhan K. Comparison of hand and semiautomatic tracing methods for creating maxillofacial artificial organs using sequences of computed tomography (CT) and cone beam computed tomography (CBCT) images. Int J Artif Organs. 2017:40:307-12.

13. Ok E, Güngör $E$, Çolak M, Altunsoy M, Nur BG, Ağlarci OS. Evaluation of the relationship between the maxillary posterior teeth and the sinus floor using cone-beam computed tomography. Surg Radiol Anat. 2014;36:907-14.
14. Von Arx T, Fodich I, Bornstein MM. Proximity of premolar roots to maxillary sinus: a radiographic survey using cone-beam computed tomography. J Endod. 2014:40:1541-8.

15. Kilic C, Kamburoglu K, Yuksel SP, Ozen T. An Assessment of the relationship between the maxillary sinus floor and the maxillary posterior teeth root tips using dental cone-beam computerized tomography. Eur J Dent. 2010;4:462-7.

16. Jung $\mathrm{YH}, \mathrm{Cho} \mathrm{BH}$. Assessment of the relationship between the maxillary molars and adjacent structures using cone beam computed tomography Imaging Sci Dent. 2012;42:219-24.

17. Sharan A, Madjar D. Correlation between maxillary sinus floor topography and related root position of posterior teeth using panoramic and cross-sectional computed tomography imaging. Oral Surg Oral Med Oral Pathol Oral Radiol Endod. 2006;102:375-81.

18. Gu Y, Sun C, Wu D, Zhu Q, Leng D, Zhou Y. Evaluation of the relationship between maxillary posterior teeth and the maxillary sinus floor using cone-beam computed tomography. BMC Oral Health. 2018;18:1-7.

19. Estrela C, Nunes CA, Guedes OA, Alencar AHG, Estrela CR, Silva RG, et al. Study of anatomical relationship between posterior teeth and maxillary sinus floor in a subpopulation of the Brazilian central region using conebeam computed tomography-part 2. Braz Dent J. 2016;27:9-15.

20. Oishi S, Ishida Y, Matsumura T, Kita S, Sakaguchi-Kuma T, Imamura T, et al. A cone-beam computed tomographic assessment of the proximity of the maxillary canine and posterior teeth to the maxillary sinus floor: lessons from 4778 roots. Am J Orthod Dentofacial Orthop. 2020;157:792-802.

21. Kim HJ, Yoon HR, Kim KD, Kang MK, Kwak HH, Park HD, et al. Personalcomputer-based three-dimensional reconstruction and simulation of maxillary sinus. Surg Radiol Anat. 2003;24:393-9.

22. Kopecka D, Simunek A, Brazda T, Rota M, Slezak R, Capek L. Relationship between subsinus bone height and bone volume requirements for dental implants: a human radiographic study. Int J Oral Maxillofac Implants. 2012;27:48-54.

23. Belgin CA, Colak M, Adiguzel O, Akkus Z, Orhan K. Three-dimensional evaluation of maxillary sinus volume in different age and sex groups using CBCT. Eur Arch Otorhinolaryngol. 2019;276:1493-9.

24. Demir UL, Akca M, Ozpar R, Albayrak C, Hakyemez B. Anatomical correlation between existence of concha bullosa and maxillary sinus volume. Surg Radiol Anat. 2015;37:1093-8.

25. Shahbazian M, Xue D, Hu Y, Cleynenbreugel J, Jacobs R. Spiral computed tomography based maxillary sinus imaging in relation to tooth loss, implant placement and potential grafting procedure. J Oral Maxillofac Res. 2010;1:e7.

26. Hamdy RM. Three-dimensional linear and volumetric analysis of maxillary sinus pneumatization. J Adv Res. 2014;5:387-95.

27. Takahashi Y, Watanabe T, limura A, Takahashi O. A study of the maxillary sinus volume in elderly persons using Japanese cadavers. Okajimas Folia Anat Jpn. 2016;93:21-7.

28. Velasco-Torres M, Padial-Molina M, Avila-Ortiz G, García-Delgado R, O’Valle F, Catena A, et al. Maxillary sinus dimensions decrease as age and tooth loss increase. Implant Dent. 2017;26:288-95.

29. Sahlstrand-Johnson P, Jannert M, Strömbeck A, Abul-Kasim K. Computed tomography measurements of different dimensions of maxillary and frontal sinuses. BMC Med Imaging. 2011;11:8.

30. AL-Qasab SJ, Mohammed AR, Kaka LN. Relationship between permanent maxillary canine and floor of the maxillary sinus through aging. Mustansiria Dent J. 2010;7:83-6.

31. Okşayan R, Sökücü O, Yeşildal S. Evaluation of maxillary sinus volume and dimensions in different vertical face growth patterns: a study of conebeam computed tomography. Acta Odontol Scand. 2017;75:345-9.

32. Costea M-C, Bondor C-I, Muntean A, Badea ME, Mesaroş A-Ş, KuijpersJagtman AM. Proximity of the roots of posterior teeth to the maxillary sinus in different facial biotypes. Am J Orthod Dentofac Orthop. 2018;154:346-55

\section{Publisher's Note}

Springer Nature remains neutral with regard to jurisdictional claims in published maps and institutional affiliations. 